\title{
Transcatheter Occlusion of a Persistent Left Superior Vena Cava to the Left Atrium Using the Transseptal Approach
}

\author{
Jeffrey D. Zampi, MD, Nathaniel R. Sznycer-Taub, MD, and Ronald G. Grifka* MD

\begin{abstract}
A persistent left superior vena cava (LSVC) is a common venous anomaly, occurring in up to $10 \%$ of patients with congenital heart defects. Usually, a LSVC drains into the coronary sinus, then to the right atrium. The LSVC can drain directly to the left atrium, resulting in a right-to-left shunt and systemic desaturation. Historically, surgery has been used to address this lesion. Transcatheter occlusion of the LSVC is an alternative to surgery. We report the novel use of the transseptal approach to access the LSVC,
\end{abstract} \\ and device occlusion using the Amplatzer Vascular Plug-II. ๑2013 Wiley Periodicals, Inc.
}

Key words: superior vena cava; transcatheter; occlusion; intervention

\section{INTRODUCTION}

A left superior vena cava (LSVC) is a common variant of venous anatomy. In the majority of cases, the LSVC drains to the coronary sinus, then to the right atrium, resulting in the normal return of venous blood to the right heart. Occasionally, the LSVC connects to the left atrium, resulting in a right-to-left shunt, systemic desaturation, and other possible sequelae. A number of reports discuss surgical treatment for a LSVC. Recently, several reports discuss transcatheter occlusion of a LSVC, using the left internal jugular vein and the off-label use of a septal occlusion device. We present a novel approach to address this vascular anomaly, using a transseptal procedure to afford access to the LSVC, then occlusion using a vascular occlusion device.

\section{CASE REPORT}

A 12-year-old young man presented to an emergency room with acutely altered mental status. There was concern that otitis media had progressed to mastoiditis. A thorough evaluation revealed several scattered, small cerebral embolic lesions, and thrombus in the right internal jugular vein and sagittal sinus. His systemic oxygen saturation was $91 \%$. A hypercoaguable work-up was unremarkable. An echocardiogram confirmed normal cardiac size and function, an intact atrial septum, and bilateral superior vena cavae with a small "bridging" left brachiocephalic vein. Through a left arm IV, an agitated saline microbubble injection dis- played dense opacification of the left atrium from the persistent LSVC draining to the left atrium. A cardiac catheterization documented the LSVC entering the superior "roof" of the left atrium (not the usual unroofed coronary sinus), a small left brachiocephalic vein, and a normal size right superior vena cava (RSVC). The presumed mechanism of the cerebral emboli was thrombus from the head and neck veins that embolized through the left brachiocephalic vein and LSVC to the left atrium, then into the systemic arterial circulation.

Due to the thrombus in the right internal jugular vein and sagittal sinus, there was concern for compromised venous drainage from the right head and arm. Since device occlusion of the LSVC could result in transient compromised drainage of the left head and arm, the LSVC was not occluded at that time. He was treated

University of Michigan Congenital Heart Center, Ann Arbor, Michigan

Conflict of interest: Nothing to report.

*Correspondence to: Ronald G. Grifka, University of Michigan Congenital Heart Center, C.S. Mott Children's Hospital, Floor 11, Cardiology, 1540 E. Hospital Drive, Ann Arbor, MI 48109-4204.

E-mail: rgrifka@med.umich.edu

Received 13 November 2012; Revision accepted 17 February 2013

DOI: $10.1002 / \mathrm{ccd} .24884$

Published online 21 February 2013 in Wiley Online Library (wileyonlinelibrary.com). 
with subcutaneous enoxaparin for 3 years. At six month intervals, follow-up head imaging studies displayed gradual and complete resolution of the right internal jugular vein and sagittal sinus thromboses, and unobstructed venous return to the RSVC. With resolution of these venous thromboses, the patient was referred for cardiac catheterization to reassess the venous anatomy and perform transcatheter occlusion of the LSVC.

The cardiac catheterization was performed using general anesthesia with $21 \%$ oxygen. His systemic oxygen saturation was $92 \%$. Using standard percutaneous technique, sheaths were placed in the right and left femoral veins. A femoral arterial line was placed for blood pressure monitoring, activated clotting time (ACT) and blood gas sampling. After performing a right heart catheterization, including measuring pressure in right $\mathrm{SVC}$ (mean $=8 \mathrm{mmHg}$ ), an end-hole catheter was advanced into the left brachiocephalic vein, where an angiogram was performed, detailing the anatomy of the LSVC (Fig. 1). The LSVC diameter varied along its length [postero-anterior $(\mathrm{AP}) \times$ lateral projection]; $8.6 \mathrm{~mm} \times 9.2 \mathrm{~mm}$ near the origin of the left brachiocephalic vein, $7.6 \mathrm{~mm} \times 8 \mathrm{~mm}$ in the middle segment, and $8.8 \mathrm{~mm} \times 10.4 \mathrm{~mm}$ just before widening at the entrance to the left atrium. The left brachiocephalic vein measured $2.5 \mathrm{~mm}$ (AP projection). A transseptal puncture was performed using standard biplane technique, and an 8 French transseptal sheath (Medtronic, Minneapolis, MN) was advanced into the left atrium; meticulous technique was used to avoid air entrance into the left atrium. The left atrial mean pressur$\mathrm{e}=9 \mathrm{~mm} \mathrm{Hg}$. After the transseptal puncture and sheath placement were safely accomplished, heparin was administered intravenously, maintaining an ACT $>225 \mathrm{sec}$. Through the transseptal sheath, a JB-1 catheter (Cook Inc., Bloomington, IN) and a 0.035" Magic wire (Boston Scientific, Natick, MA) were advanced from the left atrium into the LSVC; the LSVC mean pressure $=9 \mathrm{~mm} \mathrm{Hg}$. Over the Magic wire, the JB-1 catheter was exchanged for a balloon end-hole catheter. The balloon was inflated (with carbon dioxide) in the mid LSVC, occluding the LSVC. After 10 min of balloon occlusion, the LSVC pressure was $13 \mathrm{~mm} \mathrm{Hg}$. With this small increase in venous pressure, we concluded that occlusion of the LSVC would be well-tolerated.

With the balloon inflated in the mid-LSVC to maintain catheter stability, the transseptal sheath was advanced over the balloon catheter into the LSVC. Through the transseptal sheath, a $14 \mathrm{~mm}$ Amplatzer Vascular Plug-II (St. Jude Medical, St. Paul, MN) was implanted, which was approximately 55\% larger than the LSVC diameter. The device was well positioned; however an angiogram did not display distension of

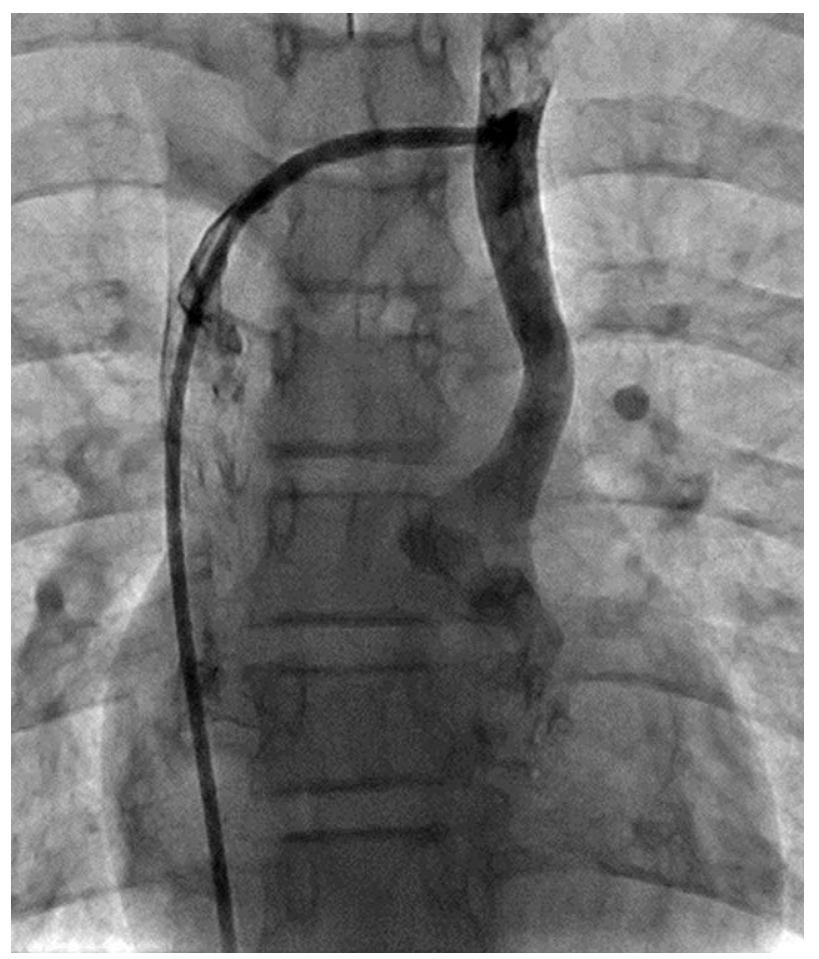

Fig. 1. Angiogram of the LSVC through an end-hole catheter positioned in the left brachiocephalic vein. The LSVC measures $8.6 \mathrm{~mm}$ near the origin of the left brachiocephalic vein, $7.6 \mathrm{~mm}$ in the middle segment, and $8.8 \mathrm{~mm}$ just before widening at the entrance to the left atrium. The left brachiocephalic vein is $2.5 \mathrm{~mm}$. Although not well displayed in this image, there is a normal caliber right SVC.

the LSVC by the device (Fig. 2). As this raised concern that the LSVC was quite distensible and the device might not maintain position in the LSVC, it was retracted into the transseptal sheath and removed. Through the same transseptal sheath, an $18 \mathrm{~mm}$ Amplatzer Vascular Plug-II was deployed in the LSVC; the superior disk was positioned just inferior to the left brachiocephalic vein, the middle disk was expanded along the length of the LSVC, and the inferior disk was positioned against the roof of the left atrium. The $18 \mathrm{~mm}$ device was approximately $90 \%$ larger than the LSVC diameter. An angiogram displayed flow through the left brachiocephalic vein, the $18 \mathrm{~mm}$ device distending the LSVC, and a small residual shunt. The device was released with no change in position. Ten minutes after device release, a repeat angiogram displayed appropriate device position, unobstructed flow through the left brachiocephalic vein and complete occlusion of the LSVC (Fig. 3). Through the transseptal sheath positioned in the left atrium, an angiogram showed the proximal disk of the device well positioned at the entrance of the LSVC to the left

Catheterization and Cardiovascular Interventions DOI 10.1002/ccd.

Published on behalf of The Society for Cardiovascular Angiography and Interventions (SCAI). 


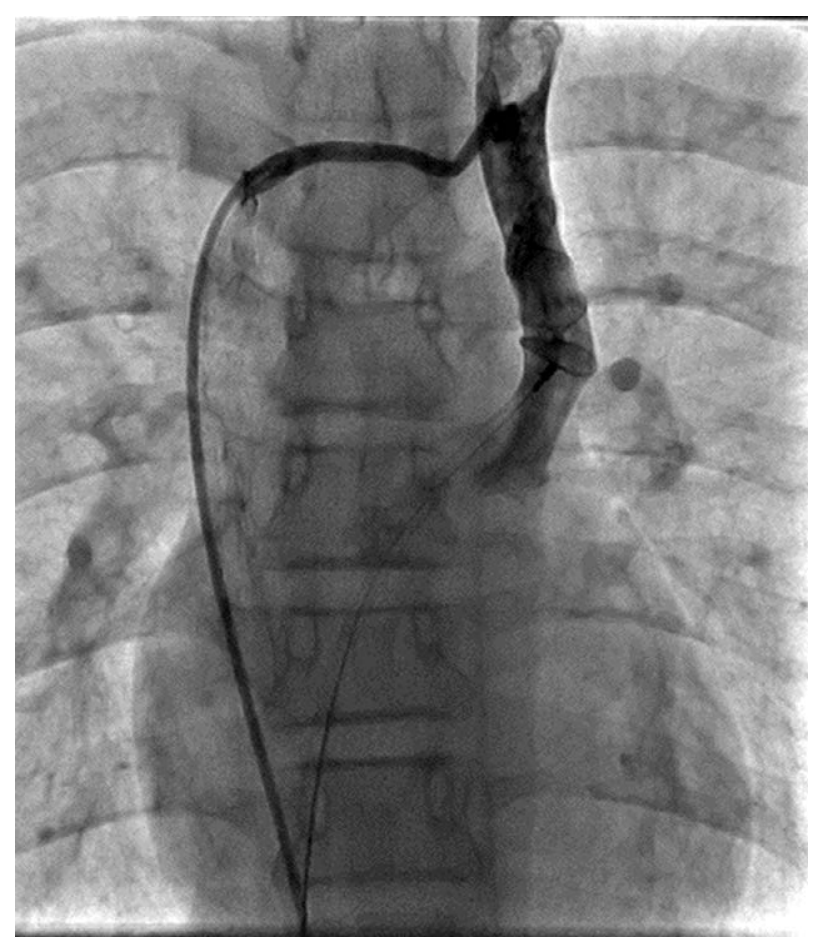

Fig. 2. The $14 \mathrm{~mm}$ Amplatzer Vascular Plug-II is deployed in the LSVC, but remains attached to the delivery cable. Contrast is injected in the left brachiocephalic vein. The device is well positioned in the mid-LSVC. However, the device is not distending the vessel, raising concern for possible device embolization after release from the delivery cable. The device was removed and replaced with an $18 \mathrm{~mm}$ device.

atrium (Fig. 4). Post-occlusion, the systemic oxygen saturation was $97 \%$.

The patient was observed overnight. The following morning, he had no symptoms or complaints, and a systemic oxygen saturation of $98 \%$. A chest X-ray confirmed appropriate device position. He was discharged to home in good condition, continuing subcutaneous enoxaparin therapy. At follow-up clinic evaluation three months after device implant, the patient was doing well. He had no complaints of headache, facial swelling, increased jugular venous pulsation, or other evidence of elevated venous pressure, and the systemic oxygen saturation was $99 \%$. An echocardiogram displayed the Amplatzer Vascular Plug-II inferior disk well opposed to the roof of the left atrium, no obvious collateral vessels, and no right-to-left shunt noted by color Doppler imaging or an agitated saline microbubble injection.

\section{DISCUSSION}

Persistence of a LSVC is a relatively common anatomical variant, with an incidence of $0.3 \%$ in autopsy studies [1]. In patients with congenital heart defects, a persistent LSVC is seen in up to $10 \%$ of patients; addi-

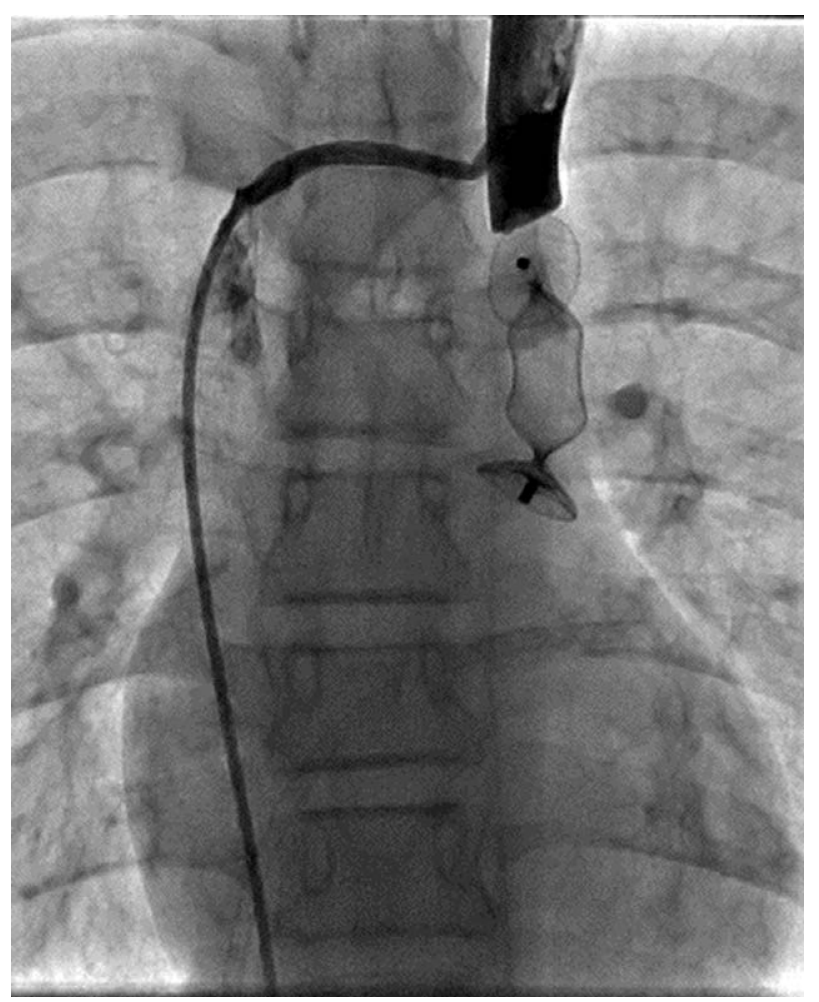

Fig. 3. Repeat angiogram of the LSVC through an end-hole catheter positioned in the left brachiocephalic vein after deployment and release of an $18 \mathrm{~mm}$ Amplatzer Vascular Plug-Il. The superior disk of the occlusion device is positioned inferior to the origin of the left brachiocephalic vein. The left brachiocephalic vein is unobstructed and there is no residual flow through the LSVC.

tional cardiac defects include atrial septal defect, bicuspid aortic valve, coarctation of aorta, coronary sinus ostial atresia, cor triatriatum, tetralogy of Fallot and heterotaxy syndrome [1-3]. Persistence of the LSVC is due to failed involution of the left anterior and left common cardinal veins during the 7th gestational week $[1,2]$. The diagnosis of a persistent LSVC is usually an incidental finding, suggested by the presence of a dilated coronary sinus on echocardiogram, or during placement of a central venous catheter from the left subclavian or jugular vein. In the vast majority of patients, a persistent LSVC drains via an intact coronary sinus to the right atrium, resulting in normal systemic venous return and no clinical sequelae. However, in $8 \%$ of patients with a persistent LSVC, the LSVC drains to the left atrium through an unroofed coronary sinus [1]. An unroofed coronary sinus has four morphologic classifications; type I, which was present in our patient, is a "completely unroofed" coronary sinus with the persistent LSVC draining directly into the left atrium $[2,4]$. This venous anomaly causes a right-toleft shunt, as desaturated systemic venous blood

Catheterization and Cardiovascular Interventions DOI 10.1002/ccd. Published on behalf of The Society for Cardiovascular Angiography and Interventions (SCAI) 


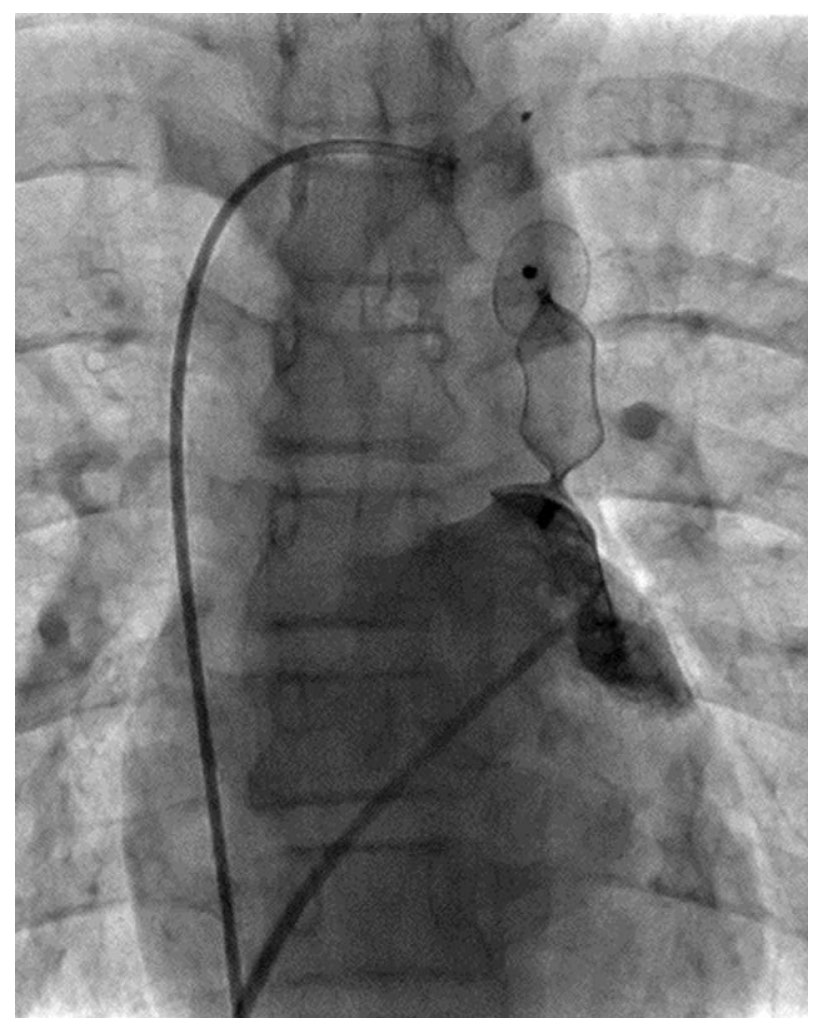

Fig. 4. Left atrial angiogram performed through the transseptal sheath positioned in the left atrium. The $18 \mathrm{~mm}$ Amplatzer Vascular Plug-II is deployed in the LSVC, with the inferior disk well opposed to the roof of the left atrium.

directly enters the left atrium. It is important to completely define the venous anatomy to avoid confusion with mirror image venous branching to a LSVC and an absent RSVC [5-7].

A LSVC draining to the left atrium is unlikely to cause clinically detectable cyanosis, but it does place patients at risk for paradoxical embolus, cerebrovascular accident, and intracranial abscess [8-10]. In the setting of significant systemic desaturation due to the right-toleft shunt, or other sequelae, repair of the LSVC is indicated. Historically, elimination of this shunt was performed surgically, by ligation of the LSVC, an intraatrial baffle to the right atrium, or translocating the LSVC to the RSVC $[4,9,11,12]$. However, the vena cava translocations and atrial baffles can become stenotic or thrombose. With the evolution of interventional catheterization techniques, there are several reports describing transcatheter occlusion of a LSVC from the left internal jugular vein approach and the off-label use of septal occlusion devices $[8,9]$.

In our patient, due to the right-to-left shunt, his baseline systemic oxygen saturation was $91 \%$. The right-to-left shunt was detected during the evaluation of an embolic stroke. Given the small bridging left brachiocephalic vein and thrombosed head and neck veins, we were concerned that occluding the LSVC at that time would further compromise venous return from the head and neck. He received enoxaparin for nearly 3 years, with resolution of the venous thromboses. To estimate the venous pressure with the LSVC occluded, we used the balloon end-hole catheter to temporarily occlude the LSVC while measuring pressures. There was minimal pressure increase in the LSVC superior to the occluding balloon, suggesting there would be no sequelae with device occlusion [4]. Following device implant, the patient has not developed evidence of elevated cerebral pressure during the hospitalization or short-term follow-up.

This is the first report describing the transseptal approach for occlusion of a LSVC, and use of the Amplatzer Vascular Plug-II. We used the transseptal approach to access the left atrium and LSVC. The transseptal technique is a well-described procedure, and is safely performed using biplane fluoroscopy [13]. By implanting the device from a transseptal approach, the distal disk was optimally positioned inferior to the left brachiocephalic vein, the proximal disk was positioned at the entrance of the LSVC to the left atrium, and the entire device position and stability were confirmed prior to release from the delivery cable. Postdevice implant, the transseptal sheath, positioned in the left atrium, was used to perform an angiogram, confirming device position. The Amplatzer Vascular Plug II was an appropriate occlusion device for this procedure. Both the $14 \mathrm{~mm}$ and $18 \mathrm{~mm}$ devices easily passed through the standard 8 French transseptal sheath. The $14 \mathrm{~mm}$ device was well positioned, but due to concerns of distensibility of this venous structure and possible device embolization, the $14 \mathrm{~mm}$ device was easily withdrawn into the transseptal sheath and the larger device delivered through the same sheath.

There are two alternative vascular approaches to perform the procedure. One approach is to access the LSVC from the left internal jugular vein. However, because of the small bridging left brachiocephalic vein and the gradual enlargement of the LSVC diameter as it entered the left atrium, we were concerned that approaching the LSVC from the left internal jugular vein would increase the risk of the occlusion device extending into the left brachiocephalic vein and/or the device embolizing to the left atrium. Also, the transseptal approach avoided placing a sheath in the left internal jugular vein, which had a higher venous pressure immediately following device occlusion. Another approach is to perform the entire procedure using a single femoral venous catheter; a balloon angiographic catheter could have been used to occlude the LSVC and simultaneously measure the change in venous

Catheterization and Cardiovascular Interventions DOI 10.1002/ccd.

Published on behalf of The Society for Cardiovascular Angiography and Interventions (SCAI). 
pressure. However, placing the long delivery sheath through the small bridging brachiocephalic vein may have made it difficult to optimally position the occlusion device in the LSVC. Due to these reasons, we chose the transseptal route for hemodynamic assessment and device implant.

\section{CONCLUSION}

Although an uncommon congenital anomaly, a persistent LSVC draining to the left atrium via a completely unroofed coronary sinus places patients at risk for mild systemic desaturation and paradoxical embolization. Occlusion of the LSVC can be performed using transcatheter techniques, avoiding a surgical procedure. In the setting of a small bridging left brachiocephalic vein, care should be taken to avoid occluding pathways that drain venous blood from the head and neck to the right atrium. The transseptal approach has several advantages to facilitate assessment of the venous anatomy and device deployment. The Amplatzer Vascular Plug-II is an appropriate device for occlusion of such a long venous anomaly.

\section{REFERENCES}

1. Geva T, Van Praagh S. Abnormal systemic venous connections. In: Moss AJ, Allen HD, editors. Moss and Adams' Heart Disease in Infants, Children, and Adolescents: Including the Fetus and Young Adult, 7th ed. Philadelphia: Wolters Kluwer Health/ Lippincott Williams \& Wilkins; 2008. pp 792-803.

2. Bonardi M, Valentini A, Camporotondo R. Unroofed coronary sinus and persistent left superior vena cava: A case report. J Ultrasound 2012;15:179-182.
3. Raghib G, Ruttenberg HD, Anderson RC, Amplatz K, Adams P Jr, Edwards JE. Termination of left superior vena cava in left atrium, atrial septal defect, and absence of coronary sinus; a developmental complex. Circulation 1965;31:906-918.

4. Ootaki Y, Yamaguchi M, Yoshimura N, Oka S, Yoshida M, Hasegaqa T. Unroofed coronary sinus syndrome: Diagnosis, classification, and surgical treatment. J Thorac Cardiovasc Surg 2003;126:1655-1656.

5. Heye T, Wengenroth M, Schipp A, Johannes Dengler T, Grenacher L, Werner Kauffmann G. Persistent left superior vena cava with absent right superior vena cava: Morphological CT features and clinical implications. Int J Cardiol 2007;116:e103e105.

6. Shah SS, Teague SD, Lu JC, Dorfman AL, Kazerooni EA, Agarwal PP. Imaging of the coronary sinus: Normal anatomy and congenital abnormalities. Radiographics 2012;32:991-1008.

7. Webb WR, Gamsu G, Speckman JM, Kaiser JA, Federle MP, Lipton MJ. Computed tomographic demonstration of mediastinal venous anomalies. AJR Am J Roentgenol 1982;139:157-161.

8. Butera G, Salvia J, Carminati M. When side matters: Contrast echocardiography with injection from the left antecubital vein to detect a persistent left superior vena cava draining to the left atrium in a patient with cerebral stroke. Circulation 2012; 125:e1.

9. Troost E, Gewillig M, Budts W. Percutaneous closure of a persistent left superior vena cava connected to the left atrium. Int J Cardiol 2006;106:365-366.

10. Vizzardi E, Fracassi F, Farina D, Nardi M, D’Aloia A, Chiari E, Nodari S, Dei Cas L. Persistence of left superior vena cava, absence of coronary sinus and cerebral ictus. Int $\mathrm{J}$ Cardiol 2008;126:e39-e41.

11. Quaegebeur J, Kirklin JW, Pacifico AD, Bargeron LM. Surgical experience with unroofed coronary sinus. Ann Thorac Surg 1979;27:418-425.

12. Reddy VM, McElhinney DB, Hanley FL. Correction of left superior vena cava draining to the left atrium using extracardiac techniques. Ann Thorac Surg 1997;63:1800-1802.

13. Duff DF, Mullins CE. Transseptal left heart catheterization in infants and children. Catheter Cardiovasc Diagn 1978;4:213-223. 